\title{
Threatened Preterm Labor
}

National Cancer Institute

\section{Source}

National Cancer Institute. Threatened Preterm Labor. NCI Thesaurus. Code 113424.

Frequent painful contractions prior to 37 weeks of gestation without cervical change. 